\title{
An empirical nexus between poverty and unemployment on economic growth
}

\author{
KEJI Sunday Anderu
}

Department of Economics, Federal University Oye-Ekiti, Ekiti State, Nigeria

Correspondence author email: sunday.keji@fuoye.edu.ng

\begin{tabular}{|l|l|l|l|l|}
\hline DOI: & Received: & Revised: & Accepted: & Published: \\
10.22437/ppd.v9i1.12005 & 03.02 .2021 & 24.04 .2021 & 25.04 .2021 & 30.04 .2021 \\
\hline
\end{tabular}

\begin{abstract}
The study examines the empirical nexus between poverty and unemployment on economic growth in Nigeria between 1980 and 2016. Auto-Regressive Distributed Lag (ARDL), Bound cointegration testing, and Error Correction Methods (ECM) were used to investigate the link between unemployment, poverty rate, and economic growth in Nigeria. Post estimation tests such as the Jarque-Bera test, Breusch-Pagan, ARCH test, and Ramsey reset test were also adopted in order to validate the research finding. The diagnostic tests further disclosed that the estimated model follows the Ordinary Least Square technique assumptions to attain efficiency and consistency of the model employed. The Jarque-Bera test suggests that residuals for both models are normally distributed, and the Breusch-Godfrey Serial Correlation (LM) test indicates that the hypothesis of no autocorrelation cannot be rejected. Interestingly, the ARDL and ECM results show that unemployment and poverty significantly impact economic growth both in the short and long run. Hence, the study recommended that the Nigeria government should ensure that adequate measures are put in place: Such as investment in education, agricultural sector reform, expansionary fiscal policy, intervention in micro-lending for small scale businesses by the government should be implemented to reduce the level of unemployment and poverty rate both in the short run and long run.
\end{abstract}

Keywords: Economic growth, Poverty, Unemployment

JEL Classification: O4, O15, J64

\section{INTRODUCTION}

Nigeria accommodates the largest population in the Sub-Sahara Africa region, with over one-hundred and eighty (180) million in 2016, based on United Nations reports. Despite this huge deposit in terms of human and natural resources, Nigeria has not driven its growth to sustainable paths; hence poverty and unemployment characterized the growth rate. It could be traced to poor resource management, excessive spending, and various government policies summersaults, making equitable production and proper income distribution unachievable (Akintoye, 2008).

Notably, Nigeria stands to be the world's paradox (World Bank, 1996). Evidence over the years continues to show that Nigeria's poverty rate contradicts the county's huge wealth of resources across the board, especially in the area of human and physical resources, which are being mismanaged and largely untapped. It is worrisome that a country with huge earnings of over $\$ 300$ billion have failed to record remarkable 
achievement in human capital development. Instead, it had rather retrogressed to be one of the ravaging poverty economies in the world (Umo, 1996). Unemployment and poverty are social phenomena. These ugly development bring about the ouster and frustrated expectations, which promote widespread indignation on the side of the trapped citizens living within the vortex of the poverty circle. In fact, conditions to take off from this object circle were being worsened by impotent poverty eradication programs with continuous neglect by the three government agencies. These predicaments resort to individual and group campaigns from different fronts, depending on situational factors and capacity (Salami, 2011).

Unemployment and poverty have nexus that can easily be causal to each other, i.e., unemployment from economic intuition could aggravate poverty. Although one might be employed and still live in abject poverty, this is connected to the scenario of underemployment. Market failure promotes unemployment and underemployment when factors of production are under-utilized. For example, low income demotivates labor as one of the key factors of production, reducing productivity. It is worthy to note that poor investment in the education and health sector of the Nigerian economy paves the way for poverty to strive (Olofin, 2012). Similarly, Yesufu (2005) opines that unemployment disrupts social progress, especially economic growth in Nigeria, enhancing general welfare loss in terms of productivity loss, thereby bringing about lower income.

Consequently, in Nigeria, studies on unemployment, poverty, and economic growth are numerous, with contrasting findings. Such studies include Bankole \& Fatai (2013), Olajide \& Oladipo (2009), Obadan \& Odusola (2005), and others. Most scholars worked on either unemployment or poverty on economic growth, with less emphasis on the impact of unemployment and poverty on economic growth in Nigeria. Also, most of these studies used narrow scope and less sophisticated econometric tools. As a result of the neglect of these important arguments, a vacuum for this research to be carried out has been discovered. Therefore, it is very pertinent to investigate the impacts of unemployment and poverty on economic growth in Nigeria between 1980 and 2016.

This study's broad objective is to evaluate the impact of poverty and unemployment on economic growth in Nigeria and determine the causal effects and remedies in Nigeria. However, the specific objective is to investigate the trend of unemployment and poverty in Nigeria and to examine whether there is a long-run relationship between poverty and unemployment on Nigerian economic growth. With the expectation that through the findings and subsequent recommendations of this study, poverty and unemployment will be reduced (alleviated) to logical points.

The study shall be grouped (divided) into five sections. Section one contains the introduction. Section two elucidates the literature review. Section three explains the research methodology, while section four discloses the analysis of the data collected. Finally, section five explains the conclusion and recommendations.

\section{LITERATURE REVIEW}

This section comprises significant concepts in this study: conceptual issues, theoretical framework, and empirical review. The conceptual issues include key concepts and terms as it's related to unemployment, poverty and economic growth. The theoretical framework reveals theories underpinning the relationship between unemployment and poverty in terms of economic. In contrast, the empirical evidence reviews scholarly articles previously written before this study.

Unemployment can be defined perspectives; hence, it is a situation whereby someone is willing and able to work but cannot secure a suitable paid job. It is quite 
worrisome when the labor age falls within the age bracket of the working population and still jobless, as it has been the order of the day in Nigeria. It is pertinent to note that unemployment can be in various forms; thus, cyclical unemployment occurs over cycles, as its name indicates. When the economy moves to a recession, many of the jobs are lost. Frictional unemployment occurs due to the normal turnover in the labor market and the time it takes for workers to find new jobs. Some workers change jobs in the course of the year in an economy. The time gap of job change is called friction, i.e., it takes time to match up potential employees with new employers. Structural unemployment resulting from industrial reorganization, typically due to technological change, rather than fluctuations in supply or demand.

Poverty has a wilder scope; hence it is a complex task to draw a specific conclusion from. As a result, series of definitions exist, which are drawn from different scholarly perspectives. Since World War defines poverty in monetary terms, the mainstream definition uses income level or consumption pattern in measuring poverty and estimating the number of the poor that fall below the poverty line with respect to income or consumption level (Grusky and Kanbur, 2006). However, complementary definitions have been drawn in recent years from other approaches (Sen, 1996). The basic needs approach by Streeten et al., 1981, the capabilities approach (Sen, 1999), and the human development approach (UNDP, 1990).

Economic growth is the general rise in the level of goods and services produced by an economy, typically a nation, over a specific period of time. It is measured as the percentage increase in the real gross domestic product (GDP), gross domestic product (GDP) adjusted for inflation. GDP is the market value of all final goods and services produced.

Empirically, Bankole \& Fatai (2013) found a positive relationship between unemployment and the economic growth of Nigeria. Engel Granger and Cointegration test and Ordinary Least Square (OLS) techniques were adopted. Whereas, Alanana (2003) argues that unemployment is potentially treacherous as it sends a worrying signal to all segments of the Nigerian Society. The rate of youth unemployment in Nigeria is high, even at the period of economic normalcy, i.e., the oil boom of the 1970s (6.2\%), 1980s (9.8\%), and the 1990s (11.5\%).

Moreover, Olajide \& Oladipo (2009) show that savings and economic growth are cointegrated and positively related in the long run. Hence, the study indicates savings is an engine to economic growth through their impact on capital formation. The study is based on the relationship between savings and growth in Nigeria through the nonparametric cointegration test and OLS method.

Bakare (2010) examines the determinants of poverty and unemployment in Nigeria. Through the time series secondary data and parsimonious error correction mechanism, the study rising nominal wages and the accelerated growth of population, which affected the supply side through a high and rapid increase in the labor force relative to the absorptive capacity of the economy, appear to be the main determinant of high unemployment poverty rate in Nigeria.

Rizwanul (2004) argued that employment and gross per capita income influenced the poverty rate across forty-one. The study adopted the OLS and correlation matrix to submit that the poverty rate falls due to the high rate of employment, which increases per capita income. Again, Muhammad \& David (2019) studied the nexus between Unemployment and Poverty in Niger State. The researchers adopted descriptive and a logistics regression model to 102 data randomly selected across the geopolitical region in the state. The study revealed that there was a proportionate link between poverty and 
unemployment in Niger state. In a related study, Sinnathurai (2013) posits that economic growth, poverty, and industrial employment have significant effects on the age dependency ratio. The study employed OLS through data drawn from forty-one countries across different continents.

In view of the above diverse approach to the subject matter, it has been observed that most of the previous scholars failed to adopt more sophisticated econometric tools in their empirical analysis. Also, only few previous researchers perform post estimation tests that revealed the validity of their empirical results. Interestingly, this study intends to close the above-observed gaps to add to the body of the literature.

\section{METHODS}

This study is built from the Solow-Swan model, a theoretical model of long-run economic growth within the framework of neoclassical economics. The long-run economic growth assumption comprises capital accumulation, labor or population growth, and productivity increases commonly referred to as technological progress. It is a core neoclassical (aggregate) production function. The model was developed independently by Robert Solow and Trevor Swan in 1956 and superseded the Keynesian Harrod-Domar model, using a simple Production function given thus:

$\mathrm{Y}=\mathrm{F}(\mathrm{K}, \mathrm{L})$

Where $\mathrm{Y}$ is income or output,

$\mathrm{K}$ denotes capital and

L denotes labor.

The model in equation (1) above is therefore specified transformed by introducing the explanatory variable poverty and unemployment that are key regressors. The model in equation (1) hereby becomes:

$\mathrm{Y}=f(\mathrm{GCF}, \mathrm{UPR})$

Other control variables to be included in the model have the inflation rate and consumption level

$\mathrm{Y}=f(\mathrm{UPR}, \mathrm{NPI}$, INFR, HCE, GCF)

The model is transformed for empirical estimation thus:

$\mathrm{RGDP}=\beta o+\beta_{1} \mathrm{UPR}+\beta_{2} \mathrm{NPI}+\beta_{3} \mathrm{INFR}+\beta_{4} \mathrm{HCE}+\beta_{5} \mathrm{GCF}+U_{t}$

Where:

RGDP $=$ Real Gross Domestic Product

UPR = Unemployment rate

NPI = National Poverty Index

INFR $=$ Inflation rate

$\mathrm{HCE}=$ Household Consumption Expenditure

GCF $=$ Gross Capital Formation

Where $U_{t}$ is the stochastic error term.

\section{Unit root test}

It is to check for the presence of a unit root in the variable, whether the variable is stationary or not. The Augmented Dickey-Fuller (ADF) is one of the measuring tools. The rule of thumb is that if the ADF test statistic is greater than the $5 \%$ critical value, we cannot reject the null hypothesis of unit root vice versa. It is empirically argued that whenever the unit root results show mixed or combination of integration order, i.e. (0) and (1), the appropriate method to adopt is ARDL Bound testing cointegration. 
After the test for the order of integration, the order of integration was a mixture of $\mathrm{I}(0)$ and $\mathrm{I}(1)$. The next step is to carry out a bounds cointegration test. This test is used to check whether there is long-run relationship among the variables specified in the model. The generalized dynamic ARDL model is specified thus:

$Y t=\gamma_{0 \mathrm{j}}+\sum_{\mathrm{i}=1}^{\mathrm{p}} \alpha_{j} Y_{1}-i+\sum_{\mathrm{i}=0}^{\mathrm{R}} \delta_{j}^{\prime} X_{1}-i+\mu \mathrm{j} t$

Where $Y_{t}$ is a vector and variables in $\left(X^{\prime} t\right)$ are allowed to be purely $I(0)$ or $I(1)$ or integrated; $\alpha$ and $\boldsymbol{\delta}$ are coefficients; $\gamma$ is the constant; $j=1,2, \ldots \mathrm{k} ; \mathbf{P}, \mathbf{R}$ are optimal lag orders; $\mu \mathrm{jt}$ is a vector of error terms, i.e., unobserved zero-mean white vector process ( serially uncorrelated or independent). Note: the lag length P, R may not be necessary the same: $\mathrm{P}$ Lag is used for the dependent variable, while $\mathrm{R}$ is used for exogenous variables.

Hypothesis: $\quad H_{0}=\beta_{1} \mathrm{j}=\beta_{2} \mathrm{j}=\beta_{3} \mathrm{j}=\beta 4 \mathrm{j}=0$

$H_{i}=\beta_{1} \mathrm{j} \neq \beta_{2} \mathrm{j} \neq \beta_{3} \mathrm{j} \neq \beta 4 \mathrm{j} \neq 0$

Where $\mathrm{j}=(1,2,3,4)$

$$
\begin{aligned}
& \Delta \log R G D P t=\beta_{01}+\beta_{11} \log R G D P_{1^{-}} i+\beta_{21} \log U N P_{2^{-}} i+\beta_{31} \log G C F_{3^{-}} i+ \\
& \beta_{41} \log I N F_{4}-i+\beta_{41} \operatorname{logNPI} I_{4}-i+\beta_{41} \log H C F_{4}-i+ \\
& \sum_{\mathrm{i}=1}^{\mathrm{p}_{1}} \beta_{1 j} \Delta \log R G D P_{1^{-}} i+\sum^{\mathrm{R} 1}{ }_{\mathrm{i}=1} \beta_{2 j} \Delta \log D S P_{1^{-}} i+ \\
& \sum_{\mathrm{i}=1}^{\mathrm{R} 2} \beta_{3 i} \Delta \log G C F_{1^{-}} i+\sum_{\mathrm{i}=1}^{\mathrm{R} 3} \beta_{4 j} \Delta \log E D S_{1^{-}} i+\mu_{1} \boldsymbol{t}
\end{aligned}
$$

\section{Error Correction Model (ECM)}

The Error Correction Model (ECM) shows the speed of adjustment from short-run to long-run equilibrium. The a priori expectation is that the ECM coefficient must be negative and significant for errors to be corrected in the long run. It indicates that the higher the ECM, the more the speed of adjustment.

\section{RESULTS AND DISCUSSION}

This section explains summary (descriptive) statistics followed by the trend analysis of Real Gross Domestic Product, Inflation Rate, Gross Capital Formation, National Poverty Index, Household Consumption Expenditure, and Unemployment Rate. Also, statistical properties of variables were examined through the Augmented Dickey-Fuller test. Followed by Autoregressive Distributed Lags bound cointegration testing and error correction model test to evaluate the dynamic nature of the relationship between the dependent variable and independent variables.

Table 1. Summary of descriptive statistics

\begin{tabular}{lrrrrrr}
\hline & RGDP & GCF & HCE & INFR & NPI & UPR \\
\hline Mean & 1926.825 & 2.740000 & 1.400000 & 19.34243 & 53.57459 & 11.45541 \\
Median & 392.6200 & 2.430000 & 2.370000 & 12.22000 & 53.60000 & 7.000000 \\
Maximum & 11064.07 & 1.570000 & 8.370000 & 72.84000 & 66.90000 & 33.15000 \\
Minimum & 7.690000 & 7.990000 & 2.530000 & 5.380000 & 40.20000 & 1.900000 \\
Std. Dev. & 3200.886 & 4.930000 & 2.310000 & 17.51549 & 6.825215 & 8.642497 \\
Skewness & 1.803241 & 1.671873 & 1.796999 & 1.707507 & -0.047946 & 0.841401 \\
Kurtosis & 5.006517 & 4.129771 & 5.007984 & 4.681148 & 2.505535 & 2.583379 \\
Jarque-Bera & 26.25893 & 19.20457 & 26.12943 & 22.33656 & 0.391107 & 4.633318 \\
Probability & 0.000002 & 0.000068 & 0.000002 & 0.000014 & 0.822379 & 0.098602 \\
Sum & 71292.52 & 1.010000 & 5.170000 & 715.6700 & 1982.260 & 423.8500 \\
Sum Sq. Dev. & 3.690000 & 8.740000 & 1.920000 & 11044.53 & 1677.008 & 2688.939 \\
Observations & 37 & 37 & 37 & 37 & 37 & 37 \\
\hline
\end{tabular}

The raw form of the data in Table 1 shows the distribution of values across the mean, median, and standard deviation. Skewness and kurtosis were displayed to explain 
the shape and height of the normal curve. While the Jarque-Bera is a test statistic for normal distribution, it shows that series are normally distributed from the results above.

LOG(RGDP)

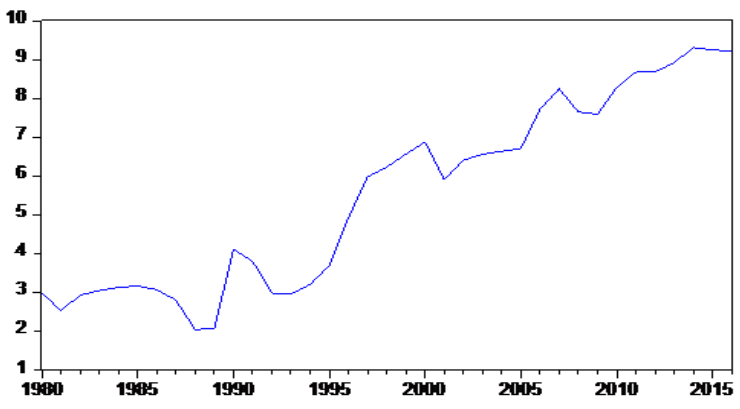

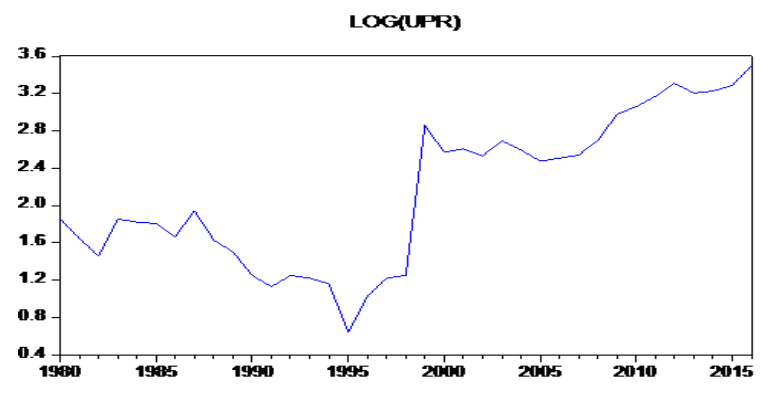

Figure 1. The real gross domestic product (RGDP) and Unemployment Rate (UPR), Nigeria, $1980-2015$

Figure 1 shows the real gross domestic product fell from the onset and continues to rise shortly in 1981 at 2.97 till early 1990. But fall sharply through 1991 and rise quickly from 1994. The economy picked up in 1995 and sustained its growth till 2000 at 6.87. The economy fell in 2001 but recovered in the following year, and it keeps growing till it got to 9.22 in 2016. Meanwhile, the Unemployment rate started from 1.856298 in 1980 , but drops through early-80's and rise sharply in 1984 . Whereas in 1986 it falls shortly and later rose the following year. It declines continuously between 1995 and 1996, with a further rise from 2000 to 2016 at 3.50 .

Table 2. Unit root results

\begin{tabular}{lcccrccc}
\hline \multirow{2}{*}{ Variable } & \multicolumn{3}{c}{ At levels } & \multicolumn{3}{c}{ 1st difference } & Level of \\
\cline { 2 - 7 } & ADF-Test & $1 \%$ C.V & $5 \%$ C.V & ADF-Test & 1\% C.V & $5 \%$ C.V & integration \\
\hline LOG(RGDP) & -0.2784 & -3.6263 & -2.9458 & -5.5228 & -3.6394 & -2.9511 & I(1) \\
LOG(HCE) & -5.4870 & -3.6263 & -2.9458 & -9.4819 & -3.6329 & -2.9484 & I(0) \\
LOG(GCF) & 0.4372 & -3.6394 & -2.9511 & -5.9111 & -3.6394 & -2.9511 & I(1) \\
LOG(INFR) & -4.3548 & -3.6268 & -2.9458 & -8.0300 & -3.6329 & -2.9484 & I(0) \\
LOG(NPI) & -2.1958 & -3.6268 & -2.9458 & -6.27043 & -3.6329 & -2.9484 & I(1) \\
LOG(UNP) & -0.6615 & -3.6268 & -2.9458 & -6.7778 & -3.6329 & -2.9484 & I(1) \\
\hline
\end{tabular}

Note: $C V$ denotes Critical Value, ADF implies Augmented Dickey-Fuller

The outcome of unit root from Table 2 discloses that log of real gross domestic, gross capital formation, national poverty index, and unemployment rate series are integrated of order one I(1). In contrast, the log of household consumption expenditure and inflation rate variables are stationary at the level. The condition for Johansen cointegration is not met, hence the ARDL-Bound testing method of cointegration analysis is adopted to investigate the long-run relationship among the series.

Table 3. The bounds cointegration test result

\begin{tabular}{lcc}
\hline ARDL Bounds Test & & \\
\hline Test Statistic & Value & $\mathrm{k}$ \\
F-statistic & 6.908617 & 5 \\
\hline Critical Value Bounds & & \\
Significance & $\mathrm{I}(0)$ Bound & $\mathrm{I}(1)$ Bound \\
\hline $10 \%$ & 2.08 & 3.00 \\
$5 \%$ & 2.39 & 3.38 \\
$2.50 \%$ & 2.70 & 3.73 \\
$1 \%$ & 3.06 & 4.15 \\
\hline
\end{tabular}


The ARDL bounds test results show the hypothesis of no long-run relationship can be rejected at 5\% significant levels among the series, as the F-statistic for the model is greater than $5 \%$ of both I (0) and I (1) bounds of 2.39 and 3.38 respectively. Therefore, there is a long-run relationship among the series.

Table 4. Long run multiplier coefficient of ARDL

\begin{tabular}{lrrrr}
\hline Variables & Coefficient & Std. Error & t-Statistic & Prob. \\
\hline LOG(HCE) & 0.581959 & 0.149587 & 3.890434 & 0.0007 \\
LOG(GCF) & 0.210207 & 0.136796 & 1.536647 & 0.1380 \\
LOG(INFR) & -0.476297 & 0.181817 & -2.619653 & 0.0153 \\
LOG(NPI) & -0.699448 & 0.947953 & -0.737850 & 0.0481 \\
LOG(UNP) & 0.376366 & 0.239259 & 1.573050 & 0.0294 \\
C & -13.14306 & 2.787882 & -4.714355 & 0.0001 \\
\hline
\end{tabular}

It can be inferred from the ARDL table that there is a positive relationship between RGDP and HCE, GCF, and UNP. In contrast, INFR and NPI had a negative relationship with RGDP. Also, all the variables were significant except GCF.

It is pertinent to note that when co-integration exists, the Engle-Granger Theorem establishes the encompassing power of the error correction mechanism over other forms of dynamic specifications. The following section reports the results of the Error Correction Mechanism.

Table 5. ARDL ECM

\begin{tabular}{lrcrr}
\hline Variables & Coefficient & Std. Error & t-Statistic & Prob. \\
\hline DLOG(RGDP(-1)) & 0.255071 & 0.062382 & 4.088841 & 0.0005 \\
DLOG(HCE) & 0.407483 & 0.093152 & 1.80052 & 0.0077 \\
DLOG(INFR) & -0.667316 & 0.052018 & -12.82846 & 0.0000 \\
DLOG(NPI) & 0.895584 & 0.744537 & 1.202874 & 0.2413 \\
DLOG(UNP) & -0.394645 & 0.120437 & 3.276783 & 0.0033 \\
CointEq(-1)* & -0.700193 & 0.089668 & -7.808716 & 0.0000 \\
\hline R-squared & 0.882838 & Mean dependent var & 0.191199 \\
Adjusted R-squared & 0.862638 & S.D. dependent var & 0.581323 \\
S.E. of regression & 0.215452 & Akaike info criterion & -0.077348 \\
Sum squared resid & 1.346173 & Schwarz criterion & 0.189283 \\
Log-likelihood & 7.353592 & Hannan-Quinn criteria. & 0.014693 \\
Durbin-Watson stat & 1.826634 & & \\
\hline
\end{tabular}

Table 5 shows the short-run (dynamics) results. The optimal lag combination for the models is obtained via the Schwartz Information Criterion (SIC). This result explains the speed of adjustment to the equilibrium in the long run. It can be deduced that there is a direct relationship between RGDP and HCE, and NPI whereas, a negative relationship is shown with INRF and UNP. Interestingly, the Household consumption expenditure indicator shows a significant positive relationship with the real growth indicator, which means that a rise in household expenses brings about a rise in economic growth.

The result further shows that a $1 \%$ increase (decrease) in HCE on average leads to a $0.407483 \%$ increase (decrease) on RGDP. It conforms to the a priori expectation.

Conversely, the inflation rate was found to negatively affect growth, though a significant relationship exists. The result implies that as the inflation rate increases, real GDP decreases vice versa. Interestingly, it portrays the set a priori expectation. In real 
terms, it shows that a $1 \%$ increase (decrease) in the consumer price index would lead to about a $0.667316 \%$ decrease (increase) in RGDP.

NPI shows that it has a direct link with RGDP but not significant. Lastly, UNP is found to have a significant effect on real growth with inverse direction. It implies that as UNP increases, RGDP decreases. The result further displays that $\%$ increase (decrease) in UNP would lead to about a $0.394645 \%$ decrease (increase) in RGDP.

The coefficient of most importance is the ECM coefficient. The ECM term is well defined, which is negative and statistically significant at a 5\% level. The coefficient is 0.700193, which indicates approximately 70.02 percent of the previous year's disequilibrium in the real gross domestic product is corrected by the estimated series. It also shows the speed at which the model converges to equilibrium. The magnitude of this coefficient implies that some of the selected variables correct nearly 70.02 percent of any disequilibrium in exchange rate fluctuations within one period (one year). The implication is that the present value of real GDP will adjust to changes in the estimated variables. It agrees with the findings of Rizwanul (2004) and Sinnathurai (2013) that established the link between poverty, unemployment, and economic progress from other economies.

Table 6. Results from diagnostic tests

\begin{tabular}{lc}
\hline Test & F-Stat (Prob) \\
\hline Jarque-Bera test & $2.625844(0.269033)$ \\
Breusch-Godfrey test & $2.478258(0.1533)$ \\
ARCH test & $2.557174(0.4378)$ \\
Ramsey-Reset test & $2.662932(0.5027)$ \\
\hline
\end{tabular}

In order to establish the reliability of ARDL, Bound test, and cointegration analysis, it is theoretically pertinent to carry out the necessary diagnostics on the results. Notably, the results of the diagnostic confirm the consistency and reliability of the findings. Jarque-Beta test suggests that both models' residuals are normally distributed with a probability value is greater than 5\% significant level. Breusch-Godfrey Serial Correlation (LM) test suggests that the hypothesis of no autocorrelation can be rejected because the probability value is greater than 5\% critical value. The Ramsey-Reset test result, whose probability value is greater than $5 \%$, indicates no functional specification in the estimated models. The ARCH test indicated that the hypothesis of the presence of heteroscedasticity could be rejected

\section{CONCLUSIONS AND RECOMMENDATIONS}

\section{Conclusions}

The overall analysis indicates a short-run and long-run relationship between the two key variables (poverty \& unemployment) and real gross domestic product in Nigeria. It is also concluded from the result that the inflation rate, national poverty index, and unemployment rate negatively affect the real gross domestic product. In contrast, the National poverty index was not significant, while gross capital formation had a positive relationship with real domestic product. Moreover, it is concluded that the Bound test confirmed that the variables estimated in the study are co-integrated. 


\section{Recommendations}

The study recommends that the government should develop the following policy framework: firstly, there is a need for expansionary fiscal policy to redesign cash flow among the economic agents. Secondly, there is a need for a well-designed microlending policy for a small-scale enterprise and an improved educational policy to address poverty and unemployment. Lastly, attention should be shifted to agricultural improvement towards diversifying the Nigerian economy, leading to improved growth through high productivity.

\section{REFERENCES}

Akintoye, IR. (2008). Reducing Unemployment through the Informal Sector: A Case Study of Nigerial. European Journal of Economics, Finance and Administrative Sciences, 11, 97-106

Alanana O. (2003). Youth unemployment in Nigeria, Some Implications for the third Millennium. Global Journal of Social Sciences, 2(1), 21-26.

Bankole A.S \& Fatai, B.O. (2013). Empirical Test of Okun's Law in Nigeria. International Journal of Economic Practices and Theories, 3(3), 227-231.

Bakare AS. (2010). The Determinants of Urban Unemployment Crisis in Nigerian: An Econometric Analysis. Journal of Emerging Trends in Economics and Managment Sciences (JETEMS), 2(3), 184-192

Central Bank of Nigeria. (2010). Statistical Bulletin Vol. 19, December, 2010. Nigeria: Central Bank of Nigeria

Grusky, D. \& Kanbur, R. (eds.), (2006). Poverty and inequality. Stanford; Stanford University Press

Muhammad,U.F \& David, J. (2019). Relationship Between Poverty and Unemployment in Niger State. Signifikan: Jurnal Ilmu Ekonomi. 8(1), 71 - 78.

Oladipo, O. S. (2009). Does saving really matter for growth in developing countries? The case of a small open economy. International Business \& Economics Research Journal, 9(4), 87-94

Olofin, O. P. (2012). Defense Spending and Poverty Reduction in Nigeria. American Journal of Economics, 2(6), 122-127.

Obadan, M.I \& Odusola, A. (2005), Productivity and Unemployment in Nigeria. National Centre for Economic Management and Administration NCEMA.

Rizwanul, I. (2004). The Nexus of Economic Growth, Employment and Poverty Reduction: An Empirical Analysis. Issues in Employment and Poverty Discussion Paper. Recovery and Reconstruction Department International Labour Office, Geneva.

Salami, C.G.E. (2011). Entrepreneurship and Youth Unemployment in Nigeria: The Missing Link. Global Journal of Management and Business Research, 11(5)

Sen, A. (1999). Development as Freedom. Oxford: Oxford University Press.

Sinnathurai V. (2013). An Empirical Study on the Nexus of Poverty, GDP Growth, Dependency Ratio and Employment in Developing Countries. Journal of Competitiveness, 5(2), 67-82

United Nations Development Programme. (1990). Human Development Report. Oxford: Oxford University Press.

United Nations. (2006). Indicators of sustainable development: guidelines and methodology. New York: United Nations 
Yesufu, T.M. (2005). Tackling unemployment in Nigeria. Opening remarks during a National Workshop on Investment for Poverty Reduction, study under the aegis of the jobs for Africa/PRESSA programme, Abuja.

(C) 2021 by the authors. Licensee JPPD, Indonesia. This article is an open-access article distributed under the terms and conditions of the Creative Commons Attribution (CC BY) license (http://creativecommons.org/licenses/by/4.0/). 